\title{
Attenuation of epidermal growth factor (EGF) signaling by growth hormone (GH)
}

\author{
Lorena González', Johanna G Miquet', Pablo E Irene', M Eugenia Díaz', \\ Soledad P Rossi², Ana I Sotelo', Mónica B Frungieri², Cristal M Hill³, Andrzej Bartke ${ }^{3}$ \\ and Daniel Turyn ${ }^{1}$ \\ ${ }^{1}$ Instituto de Química y Fisicoquímica Biológicas (UBA-CONICET), Facultad de Farmacia y Bioquímica, \\ Buenos Aires, Argentina \\ IInstituto de Biología y Medicina Experimental, CONICET, Ciudad de Buenos Aires, Argentina \\ ${ }^{3}$ Departments of Internal Medicine and Physiology, Geriatrics Research, School of Medicine, \\ Southern Illinois University, Springfield, Illinois, USA
}

Correspondence should be addressed to L González Email Igonzalez@qb.ffyb.uba.ar

\begin{abstract}
Transgenic mice overexpressing growth hormone (GH) show increased hepatic protein content of the epidermal growth factor receptor (EGFR), which is broadly associated with cell proliferation and oncogenesis. However, chronically elevated levels of GH result in desensitization of STAT-mediated EGF signal and similar response of ERK1/2 and AKT signaling to EGF compared to normal mice. To ascertain the mechanisms involved in $\mathrm{GH}$ attenuation of EGF signaling and the consequences on cell cycle promotion, phosphorylation of signaling mediators was studied at different time points after EGF stimulation, and induction of proteins involved in cell cycle progression was assessed in normal and GH-overexpressing transgenic mice. Results from kinetic studies confirmed the absence of STAT3 and 5 activation and comparable levels of ERK1/2 phosphorylation upon EGF stimulation, which was associated with diminished or similar induction of c-MYC, c-FOS, c-JUN, CYCLIN D1 and CYCLIN E in transgenic compared to normal mice. Accordingly, kinetics of EGF-induced c-SRC and EGFR phosphorylation at activating residues demonstrated that activation of these proteins was lower in the transgenic mice with respect to normal animals. In turn, EGFR phosphorylation at serine 1046/1047, which is implicated in the negative regulation of the receptor, was increased in the liver of GH-overexpressing transgenic mice both in basal conditions and upon EGF stimulus. Increased basal phosphorylation and activation of the p38-mitogen-activated protein kinase might account for increased Ser 1046/1047 EGFR. Hyperphosphorylation of EGFR at serine residues would represent a compensatory mechanism triggered by chronically elevated levels of GH to mitigate the proliferative response induced by EGF.
\end{abstract}

\section{Key Words}

- growth hormone (GH)

- epidermal growth factor (EGF)

- transgenic mice

- Ser 1046/1047 EGFR phosphorylation

- signal transduction

- liver

\section{Introduction}

The epidermal growth factor receptor (EGFR), also called ERBB-1, belongs to a family of tyrosine kinase receptors (RTKs) that includes three additional proteins, ERBB-2,
ERBB-3 and ERBB-4 (Yarden \& Sliwkowski 2001). Phosphorylation of ERBB receptors leads to the recruitment of a number of docking and signaling proteins such as 
GRB-2, SHC, protein tyrosine phosphatase (PTP)-1B, PLC $\gamma$ and SRC, among others. These interactions trigger intracellular signaling cascades such as the RAS/RAF/MEK/ ERK (p44/p42 MAPK), p38 MAPK, the PKC, the PI3K/AKT and the STAT pathways (Yarden \& Pines 2012), which, in turn, induce several transcriptional regulators like c-MYC, c-FOS and c-JUN. These transcription factors promote the expression of molecules like CYCLINs that mediate cell cycle entrance from quiescence (G0) and subsequent DNA synthesis, cell division, and thus, cell proliferation. These signaling pathways are also involved in the promotion of cell growth and differentiation.

EGFR has been implicated in the development of many types of cancer (Hynes \& MacDonald 2009). The receptor undergoes different alterations including gene amplification, structural rearrangements and somatic mutations in human carcinomas; moreover, some types of tumors produce EGF in excess, which leads to an increased activation of the receptor (Henson \& Gibson 2006). These modifications promote constitutive receptor activation, a process that drives cancer development and contributes to its progression and resistance to antineoplastic therapies (Arteaga \& Engelman 2014). In particular, the EGFR system has been implicated in hepatocarcinogenesis since early stages of the disease (Berasain \& Avila 2014). ERBB1 has been frequently found overexpressed in hepatocellular carcinoma (HCC), which correlated with high proliferating activity, intrahepatic metastasis, poor carcinoma differentiation and bad prognosis (Ito et al. 2001, Buckley et al. 2008).

Growth hormone (GH), a pituitary polypeptide involved in longitudinal growth promotion and metabolic processes, modulates EGFR expression, activation and ligand-induced receptor internalization (Jansson et al. 1988, Huang et al. 2003, González et al. 2010, Zerrad-Saadi et al. 2011). Hepatic EGF binding is diminished in hypophysectomized and in partially GH-deficient mutant 'little' (lit/lit) mice due to reduced EGFR levels; GH replacement therapy restores EGF binding to liver cells in these animals (Jansson et al. 1988). In accordance, hepatic EGFR expression is increased in transgenic mice overexpressing $\mathrm{GH}$, but decreased in GH receptor-knockout mice (González et al. 2010). GH was also shown to induce tyrosine phosphorylation of the epidermal growth factor receptor, which may allow it to serve as a scaffold for GH signaling (Yamauchi et al. 1998). Moreover, GH was described to control EGFR signaling by ERK1/2-mediated phosphorylation on threonine residues (Huang et al. 2003, 2004, 2006), which delays EGFR downregulation and therefore potentiates acute EGF signaling (Huang et al. 2003, 2004, 2006, Li et al. 2008).

In addition to its physiological effects over growth and metabolism, GH was proposed to be involved in tumorigenesis and tumor progression. GH overexpression has been associated with cancer in animals as well as in humans (Jenkins 2006, Loeper \& Ezzat 2008). Transgenic mice overexpressing $\mathrm{GH}$ are more likely to develop cancer, and they have an increased tendency to develop liver tumors, including hepatocellular carcinoma, at advanced ages (Snibson 2002, Bartke 2003). Considering GH modulation of EGFR expression and activation, as well as the receptor involvement in several oncogenic processes, growth hormone modulation of EGFR expression and signaling has been studied by our research group in transgenic mice overexpressing the hormone (González et al. 2010, Díaz et al. 2012). Those studies aimed to determine if increased EGFR levels induced by high GH concentration resulted in increased EGF signaling and upregulation of mitogenic signals. Contrary to our expectations, results showed that high circulating levels of GH and EGFR overexpression were not associated with an increased response to an acute EGF stimulus. Actually, EGF stimulation caused similar levels of AKT, and ERK1/2 phosphorylation in normal and transgenic mice, whereas STAT3 and STAT5 were not activated as a consequence of EGF administration in the GH-overexpressing transgenic mice (González et al. 2010). Kinetic studies of EGF-induced PI3K-AKT pathways were conducted to dissect possible mechanisms involved in the attenuation of AKT-mediated EGF signaling by continuously high GH levels (Díaz et al. 2012). Transient recruitment and activation of the tyrosine phosphatase SHP-2 by the EGFR were proposed to be involved in this process (Díaz et al. 2012).

In the present study, kinetic studies of EGF-induced signaling mediators were performed to ascertain possible molecular mechanisms underlying the previously described effects of GH overexpression over ERK1/2 and STATs activation by EGF (González et al. 2010). To determine if the effects of chronically elevated GH levels on EGF signaling might affect the promotion of cell proliferation by the growth factor, induction of early genes and CYCLINs involved in cell cycle progression were also assessed in the liver of transgenic mice overexpressing $\mathrm{GH}$ after EGF stimulation. http://joe.endocrinology-journals.org DOI: $10.1530 / J O E-16-0606$ (c) 2017 Society for Endocrinology Printed in Great Britain
Published by Bioscientifica Ltd 


\section{Materials and methods}

\section{Reagents}

Recombinant human EGF, Trizma base, HEPES, Tween 20, Triton X-100, sodium dodecyl sulfate (SDS), glycine, ammonium persulphate, aprotinin, phenylmethylsulphonyl fluoride (PMSF), sodium orthovanadate, 2-mercaptoethanol, molecular-weight markers and BSA-fraction V were obtained from Sigma Chemical. PVDF membranes and high-performance chemiluminescence film were from Amersham Biosciences (GE Healthcare). ECL Plus Western Blotting Substrate was from Pierce, Thermo Fisher Scientific. Mini Protean apparatus for SDS-polyacrylamide electrophoresis, miniature transfer apparatus, acrylamide, bis-acrylamide and TEMED were obtained from Bio-Rad Laboratories. Secondary antibodies conjugated with HRP, anti-EGFR, anti-p38alpha, anti-phosphoT180/Y182-p38 and antiSTAT5 antibodies were purchased from Santa Cruz Biotechnology Laboratories. The anti-phosphoY694/696STAT5 antibody was from Millipore. The anti-p44/42 MAPK (anti-ERK1/2), anti-phosphoT185Y187-p44/42 MAPK (anti-phospho-ERK1/2), anti-phosphoY705-STAT3, anti-phosphoY845-EGFR, anti-phosphoS1046/1047EGFR, anti-cMyc, anti-cJun and anti-cFos antibodies were from Cell Signaling Technology. M1701 MMLV reverse transcriptase $10,000 \mu$ was obtained from Promega BioSciences. The SYBR Green Master Mix reagent was from Applied Biosystems and the bicinchoninic acid (BCA) protein assay kit was obtained from Thermo Scientific, Pierce Protein Research Products.

\section{Animals}

Phosphoenolpyruvate carboxykinase (PEPCK)-bGH mice containing the bovine $\mathrm{GH}(\mathrm{bGH})$ gene fused to control sequences of the rat pepck gene have been previously described (McGrane et al. 1990). Normal siblings of transgenic mice were used as controls. Female adult animals (4-6 months old) were used. The mice were housed 3-5 per cage in a room with controlled light (12-h light/day) and temperature $\left(22 \pm 2^{\circ} \mathrm{C}\right)$. The animals had free access to food (Lab Diet Formula 5001 containing a minimum of $23 \%$ protein, $4.5 \%$ fat and a maximum of $6 \%$ crude fiber, from Purina Mills Inc., St Louis, MO, USA) and tap water. The appropriateness of the experimental procedure, the required number of animals used and the method of acquisition were in compliance with federal and local laws and with institutional regulations.

\section{Animal treatments}

PEPCK-bGH transgenic mice and their normal littermate controls were fasted for $6 \mathrm{~h}$ prior receiving an i.p. injection of recombinant human EGF at $2 \mathrm{mg} / \mathrm{kg} \mathrm{BW}$ in $0.9 \% \mathrm{w} / \mathrm{v} \mathrm{NaCl}$. Animals were killed by cervical dislocation under isoflurane anesthesia 2.5, 5, 10 and 15 min after administration of EGF (Díaz et al. 2012) to study the phosphorylation of EGF signaling mediators or after $1 \mathrm{~h}$ or $4 \mathrm{~h}$ to study the expression of early genes and Cyclins involved in the induction of cell cycle progression (Díaz et al. 2014). Non-stimulated mice were used to evaluate basal conditions (considered as time 0). The livers were removed and stored frozen at $-70^{\circ} \mathrm{C}$ until homogenization.

\section{Preparation of liver extracts}

Liver samples were homogenized at the ratio $0.1 \mathrm{~g} / \mathrm{mL}$ in buffer composed of $1 \% \mathrm{v} / \mathrm{v}$ Triton, $0.1 \mathrm{~mol} / \mathrm{L}$ Hepes, $0.1 \mathrm{~mol} / \mathrm{L}$ sodium pyrophosphate, $0.1 \mathrm{~mol} / \mathrm{L}$ sodium fluoride, $0.01 \mathrm{~mol} / \mathrm{L}$ EDTA, $0.01 \mathrm{~mol} / \mathrm{L}$ sodium vanadate, $0.002 \mathrm{~mol} / \mathrm{L}$ PMSF and 0.035 trypsin inhibitory units $/ \mathrm{mL}$ aprotinin $(\mathrm{pH} 7.4)$ at $4^{\circ} \mathrm{C}$. Liver homogenates were centrifuged at $100,000 \boldsymbol{g}$ for $40 \mathrm{~min}$ at $4^{\circ} \mathrm{C}$ to remove insoluble material. Protein concentration of supernatants was determined by the BCA protein assay kit. An aliquot of solubilized liver was diluted in Laemmli buffer, boiled for $5 \mathrm{~min}$ and stored at $-20^{\circ} \mathrm{C}$ until electrophoresis.

\section{Immunoblotting}

Samples were subjected to electrophoresis in SDSpolyacrylamide gels. Electrotransference of proteins from gel to PVDF membranes and incubation with antibodies was performed as previously described (González et al. 2010). Immunoreactive proteins were revealed by enhanced chemiluminescence. Band intensities were quantified using Gel-Pro Analyzer 4.0 software (Media Cybernetics, Silver Spring, MD, USA). To reprobe with other antibodies, the membranes were washed with acetonitrile for $10 \mathrm{~min}$ and then incubated in stripping buffer $(2 \% \mathrm{w} / \mathrm{v}$ SDS, $0.100 \mathrm{~mol} / \mathrm{L} 2$-mercaptoethanol, $0.0625 \mathrm{~mol} / \mathrm{L}$ Tris- $\mathrm{HCl}, \mathrm{pH} 6.7$ ) for $40 \mathrm{~min}$ at $50^{\circ} \mathrm{C}$ while shaking, washed with deionized water and blocked with BSA.
() 2017 Society for Endocrinology Printed in Great Britain 


\section{RNA isolation and quantitative RT-PCR}

Total RNA was extracted from $50 \mathrm{mg}$ liver tissue using TRIzol reagent (Life Technologies) according to the manufacturer's instructions. The ratio of the absorbance at 260 and $280 \mathrm{~nm}(\mathrm{~A} 260 / 280)$ was used to assess RNA purity. RNA integrity was evaluated by electrophoresis on $1 \% \mathrm{w} / \mathrm{v}$ agarose gel. RT reaction was performed using $2 \mu \mathrm{g}$ of total RNA, random hexamer primers (Biodynamics SRL, Buenos Aires, Argentina) and the M-MLV reverse transcriptase enzyme (Promega, 200U/mL) as previously described (Frungieri et al. 2002).

cDNA was amplified by quantitative real-time PCR (qPCR) using SYBR Green Master Mix Reagent (Applied Biosystems) and the ABI PRISM 7500 Sequence Detection System (Applied Biosystems). qPCR assays were performed using oligonucleotide primers for CyclinD1 (Ccnd1) (5'-GCGAAGTGGAGACCATCCG and 5'-GGTCTC CTCCGTCTTGAGC), CyclinE (Ccne1) (5'-GGCGGACACAGCTTCGGGTC and 5'-TGGGTCTTGCAAAAACACGGCCA), Cyclophilin A (5'-GCGTCTCCTTCGAGCTGTT and 5'-AAGTCACCACCCTGGCAC). Cyclophilin A was chosen as the housekeeping gene (Díaz et al. 2014). Reaction data were collected and analyzed using complementary computer software (Sequence Detection Software, Applied Biosystems, version 1.3). Applying the mathematical model of Pfaffl (2001), relative levels of mRNA expression were determined for each sample by

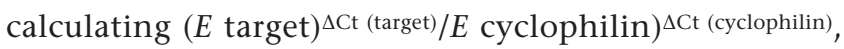
where $E$ is the efficiency of the primer set, and $\Delta \mathrm{Ct}=\mathrm{Ct}$ (normalization cDNA)-Ct (experimental cDNA). The amplification efficiency of each primer set was calculated from the slope of a standard amplification curve of log microliters of cDNA per reaction vs Ct value $\left(E=10^{(1 / \text { slope })}\right)$. Optimal reaction efficiencies are between 1.9 and 2.1 .

\section{Statistical analysis}

Experiments were carried out analyzing all groups of animals in parallel, $\mathrm{n}$ representing the number of different individuals used in each group. Results are presented as mean \pm S.E.M. of the number of samples indicated. Statistical analyses were performed by ANOVA followed by the Newman-Keuls multiple comparison test using the GraphPad Prism 4 statistical program by GraphPad Software. Student's $t$-test was used when only two groups were analyzed. Data were considered significantly different if $P<0.05$.

\section{Results}

\section{EGF-induced STATs and ERK1/2 phosphorylation kinetic studies in normal and transgenic mice}

We have previously demonstrated that phosphorylation of STAT3 and STAT5 was not induced in the liver of transgenic mice overexpressing GH $10 \mathrm{~min}$ after EGF stimulation (González et al. 2010). Similar results were described for AKT activation. When EGF-induced AKT activation was analyzed at different times, we observed that phosphorylation at residues Ser473 and Thr308 of AKT augmented early after EGF injection and remained activated 15 min after stimulation in normal mice (Díaz et al. 2012). In the liver of GH-overexpressing transgenic mice, AKT phosphorylation was early but transiently induced by EGF, showing low phosphorylation levels after $10 \mathrm{~min}$ (Díaz et al. 2012). Considering these previous studies, EGFinduced STAT3 and STAT5 phosphorylation was analyzed at different time points after injection to ascertain if EGF induces STATs activation in transgenic mice with different kinetics than that in normal animals. Normal and transgenic mice were stimulated with EGF during $2.5,5,10$ or $15 \mathrm{~min}$, and liver extracts were analyzed by immunoblotting. Phosphorylation levels of the STATs were related to protein content to plot the data from different experiments. STAT3 and STAT5 protein content did not vary between normal and transgenic mice or during the stimulation period (Fig. 1A and B). In normal mice, STAT3 phosphorylation was significantly induced 10 min after EGF injection, and decreased afterward (Fig. 1A). STAT5 was also induced by EGF $10 \mathrm{~min}$ after stimulation which persisted at $15 \mathrm{~min}$ (Fig. 1B). On the contrary, neither STAT3 nor STAT5 phosphorylation was induced by EGF in the liver of transgenic mice at any time studied (Fig. 1A and B).

Similarly, EGF-induced ERK1/2 phosphorylation was studied at different times after stimulation with EGF. ERK1 and ERK2 (44 and $42 \mathrm{kDa}$, respectively) are activated by phosphorylation at Thr202 and Tyr204. In contrast to results obtained for the STATs, ERK1 and ERK2 activation was significantly induced in the liver of normal and transgenic mice with similar kinetics and to a similar extent (Fig. 1C). However, as ERK1 and ERK2 protein content (in the liver of transgenic mice is higher than in normal animals) (Fig. 1C; González et al. 2010), results expressed as the relationship between phosphorylation and protein content revealed a decreased phosphorylation ratio for the transgenic mice (Fig. 1C). Therefore, a lower proportion of total ERK1/2 is activated by EGF in the transgenic mice.

Published by Bioscientifica Ltd 
A
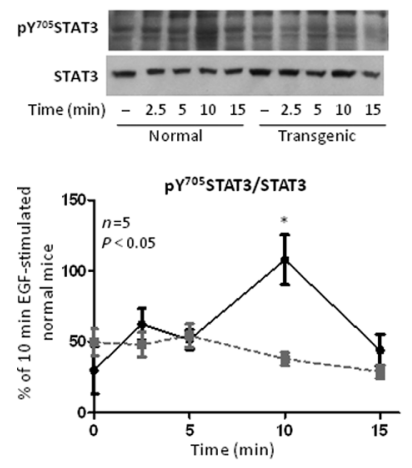

B
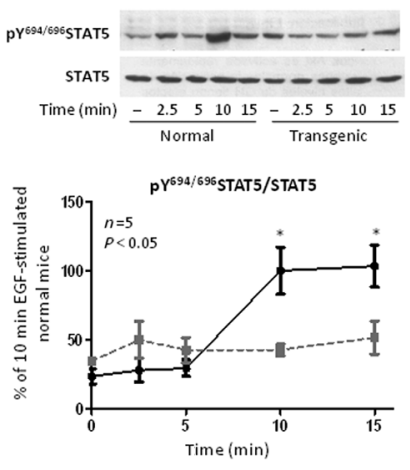

C
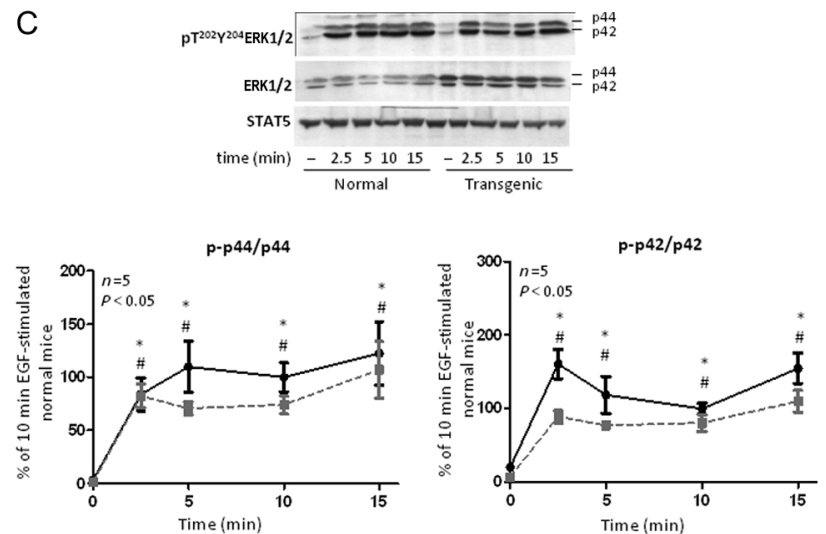

Figure 1

Kinetics of STAT3, STAT5 and ERK1/2 EGF-induced phosphorylation related in normal and GH-overexpressing mice liver. Normal and PEPCK-bGH transgenic mice were injected i.p. with saline or EGF ( $2 \mathrm{mg} / \mathrm{kg} \mathrm{BW})$, killed after 2.5, 5, 10 or $15 \mathrm{~min}$, and the livers were removed. Equal amounts of solubilized liver protein were separated by SDS-PAGE and subjected to immunoblotting analysis. Reprobing with anti-STATs antibody demonstrated similar protein loading. Representative immunoblots are shown. Quantification was performed by scanning densitometry and expressed as percent of values measured for EGF (10 min)-stimulated normal mice. Data resulting from quantification analysis were used to calculate the PY705STAT3/STAT3 (A), the pY694/696STAT5/STAT5 (B), pT202Y204ERK1/ERK1 and pT202Y204ERK2/ERK2 (C) ratios for normal (black circle) and PEPCK-bGH transgenic mice (grey square). Data are expressed as the mean \pm s.E.M. of the indicated number of subsets $(n)$ of different individuals. Statistical analysis was performed by ANOVA. *and \# denote significant difference at $P<0.05$ compared to non-stimulated control and transgenic mice, respectively.

\section{Effects of high GH levels over EGF induction of proteins that trigger cell cycle progression}

Several transcriptional regulators involved in the control of the cell cycle like c-MYC, c-FOS and c-JUN are induced as a consequence of STAT3, STAT5, ERK1/2 and AKT activation (Karin 1995, Bromberg \& Darnell 2000, Calò et al. 2003, Liang \& Slingerland 2003); therefore, the protein content of these transcription factors was evaluated in the liver of normal and GH transgenic mice after EGF administration.
c-MYC, c-FOS and c-JUN expression was measured in basal conditions and after $1 \mathrm{~h}$ of EGF stimulation in the liver of normal and transgenic mice. Basal c-MYC, c-JUN and c-FOS protein content was barely detected when samples were analyzed in parallel with those from stimulated mice; therefore, no significant differences in basal protein content could be described between normal and transgenic mice. The transcription factor c-MYC was significantly induced by EGF in normal mice, whereas its
A
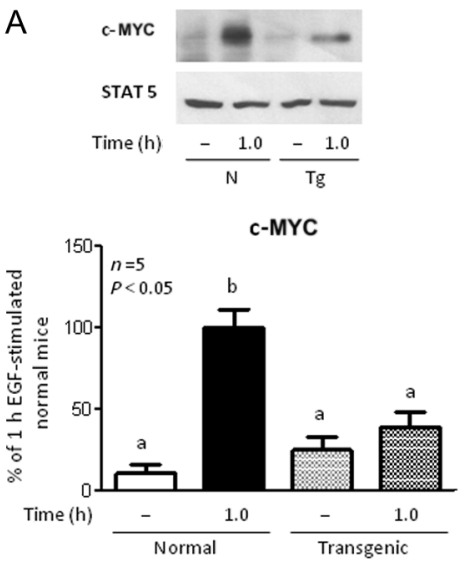

B
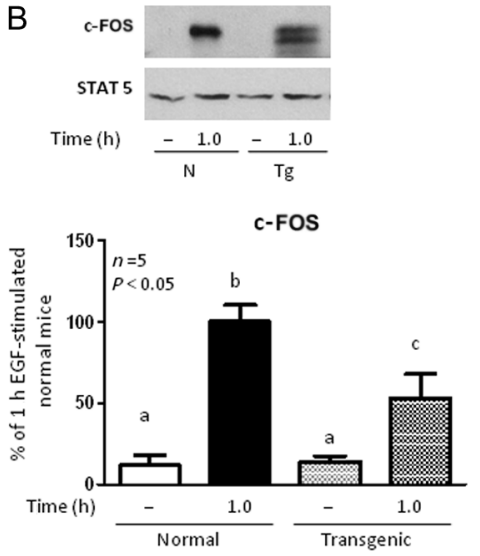

C
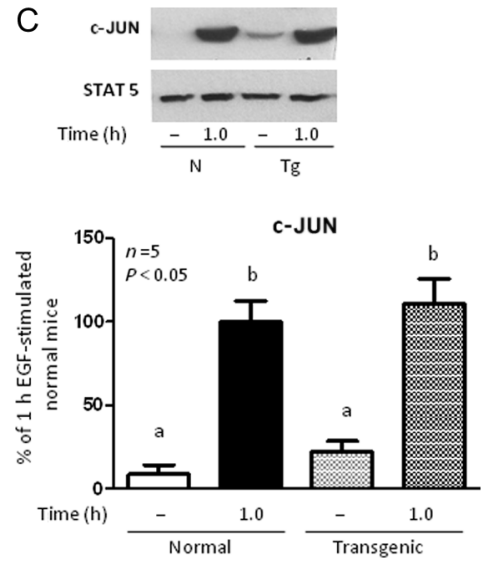

Figure 2

Hepatic c-MYC, c-FOS and c-JUN protein content in normal and GH-overexpressing mice. Normal and PEPCK-bGH transgenic mice were injected i.p. with saline or EGF ( $2 \mathrm{mg} / \mathrm{kg} \mathrm{BW})$, killed after $1 \mathrm{~h}$ and the livers were removed. Equal amounts of solubilized liver protein were separated by SDS-PAGE and subjected to immunoblotting analysis with antibodies against c-MYC (A), c-FOS (B) and c-JUN (C). Reprobing with anti-STAT5 antibody demonstrated similar protein loading in all lanes. Representative immunoblots are shown. Quantification was performed by scanning densitometry and expressed as percent of values measured for EGF-stimulated normal mice. Data are expressed as the mean \pm S.E.M. of the indicated number of subsets ( $n$ ) of different individuals. Statistical analysis was performed by ANOVA. Different letters denote significant difference at $P<0.05$.

http://joe.endocrinology-journals.org DOI: $10.1530 / \mathrm{JOE}-16-0606$
๑ 2017 Society for Endocrinology Printed in Great Britain
Published by Bioscientifica Ltd 
induction by EGF was not different from basal in the liver of transgenic mice (Fig. 2A). c-FOS significantly increased upon EGF stimulation in normal and transgenic mice, although levels achieved in GH-overexpressing mice were lower than those determined for normal mice (Fig. 2B). c-JUN protein content was also significantly induced by EGF in normal and transgenic mice, but in this case, the levels attained were similar in normal and transgenic mice (Fig. 2C).

As a consequence of c-MYC induction, the transcription of genes that encode D-type CYCLINs and CYCLIN E is triggered (Nasi et al. 2001). Additionally, c-JUN was shown to regulate the transcriptional level of CYCLIN D1. Heterodimerization with c-FOS further increases the transcriptional capacity of c-JUN through the formation of more stable dimers (Shaulian \& Karin 2001). As CYCLIN D1 and CYCLIN $\mathrm{E}$ are induced by the early genes previously assessed, and considering their relevance to commit cells to progress through the cell cycle and therefore to proliferate, EGF induction of these proteins was determined in the liver of normal and transgenic mice. CYCLIN D1 and CYCLIN E levels were assessed by immunoblotting and quantitative RT-PCR (RT-qPCR) in basal conditions and after $4 \mathrm{~h}$ of EGF administration. CYCLIN D1 basal levels were not significantly different between normal and transgenic mice when protein levels were analyzed by immunoblotting in parallel with stimulated samples (Fig. 3A), but its expression was found to be higher in the transgenic mice when assessed by RT-qPCR (Fig. 3B). CYCLIN E basal levels were clearly increased in transgenic mice, this was observed both by immunoblotting (Fig. 3C) and RT-qPCR studies (Fig. 3D) and is in coincidence with previous results from our research group (Miquet et al. 2013). Upon EGF injection, CyclinD1 expression was significantly induced both in normal and transgenic mice, with no significant differences between genotypes, assessed either by immunoblotting or RT-qPCR (Fig. 3A and B). On the contrary, CyclinE expression was induced by EGF in normal mice but not in transgenic animals (Fig. 3C and D), either when assessed by immunoblotting or by RT-qPCR.

\section{Kinetic studies of phosphorylation of c-SRC, EGFR and p38 induced by EGF in normal and transgenic mice}

c-SRC is a cytoplasmic, membrane-associated, nonreceptor tyrosine kinase that acts as a cotransducer of mitogenic signals emanating from a number of tyrosine kinase polypeptide growth factor receptors such as the EGFR (Belsches et al. 1997). To ascertain if inhibitory mechanisms are acting over c-SRC in the liver of transgenic mice, EGF-induced phosphorylation of the tyrosine kinase was studied after stimulation for different intervals with the growth factor (Fig. 4A). In coincidence with previous reports from our research group (Miquet et al. 2008), c-SRC basal phosphorylation and protein levels were increased in the liver of transgenic mice (Fig. 4A). Kinetic analysis of c-SRC phosphorylation by EGF revealed that its activation reached a maximum $10 \mathrm{~min}$ after injection in the liver of normal mice (Fig. 4A). On the contrary, EGF stimulation was not able to significantly induce c-SRC phosphorylation over basal levels in the GH-overexpressing animals (Fig. 4A). When phosphorylation levels were expressed
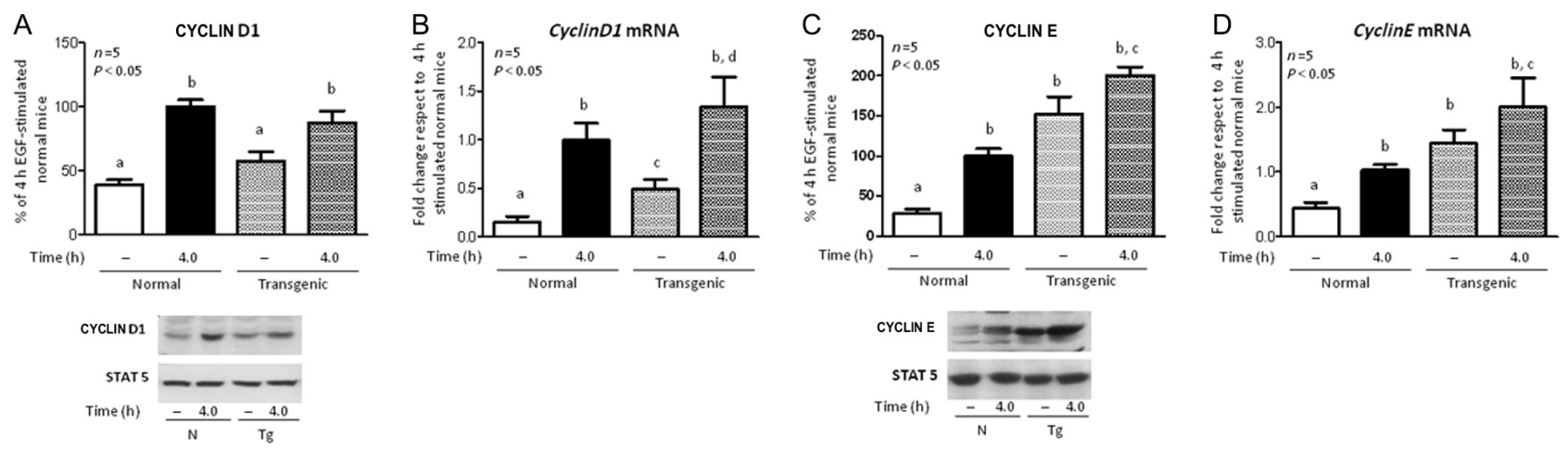

Figure 3

Hepatic CYCLIN D1 and CYCLIN E protein and mRNA expression. Normal and PEPCK-bGH transgenic mice were injected i.p. with saline or EGF (2 mg/kg $B W)$, killed after $4 \mathrm{~h}$ and the livers were removed. Equal amounts of solubilized liver protein were separated by SDS-PAGE and subjected to immunoblotting analysis with antibodies against CYCLIN D1 (A) and CYCLIN E (C). Reprobing with anti-STAT5 antibody demonstrated similar protein loading in all lanes. Representative Western blots are shown. Quantification was performed by scanning densitometry and expressed as percent of values measured for EGF-stimulated normal mice. CyclinD1 and CyclinE mRNA expression was also assessed by RT-qPCR (B and D). Results were expressed as fold change vs values measured for EGF-stimulated normal mice. Data are expressed as the mean \pm s.E.M. of the indicated number of subsets ( $n$ ) of different individuals. Statistical analysis was performed by ANOVA. Different letters denote significant difference at $P<0.05$. 
A

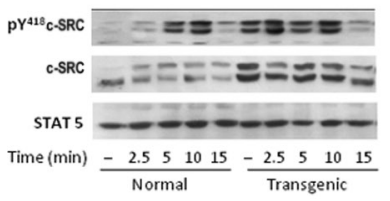

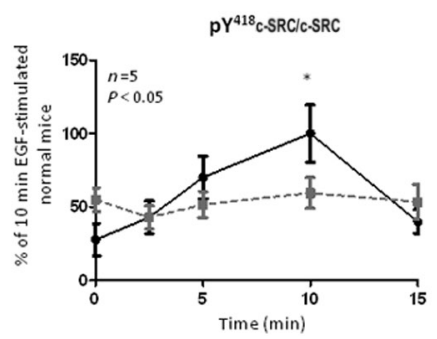

B

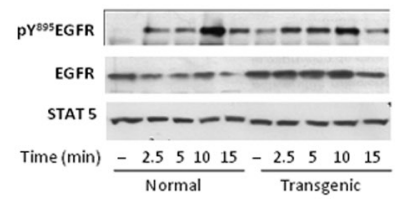

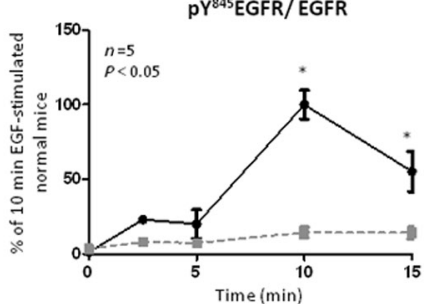

Figure 4

Kinetics of c-SRC and Y845-EGFR EGF-induced phosphorylation in normal and GH-overexpressing mice liver. Normal and PEPCK-bGH transgenic mice were injected i.p. with saline or EGF ( $2 \mathrm{mg} / \mathrm{kg} \mathrm{BW}$ ), killed after 2.5, 5, 10 or $15 \mathrm{~min}$ and the livers were removed. Equal amounts of solubilized liver protein were separated by SDS-PAGE and subjected to immunoblotting analysis. Reprobing with anti-STAT5 antibody demonstrated similar protein loading in all lanes. Representative immunoblots are shown. Quantification was performed by scanning densitometry and expressed as percent of values measured for EGF (10 min)-stimulated normal mice. Data resulting from quantification analysis were used to calculate the $\mathrm{pY}{ }^{418} \mathrm{C}-\mathrm{SRC} / \mathrm{c}-\mathrm{SRC}$ (A) and the $\mathrm{pY}{ }^{845} \mathrm{EGFR} / \mathrm{EGFR}$ (B) ratio for normal (black circle) and PEPCK-bGH transgenic mice (grey square). Data are expressed as the mean \pm S.E.M. of the indicated number of subsets $(n)$ of different individuals. Statistical analysis was performed by ANOVA. * denotes significant difference at $P<0.05$ compared to non-stimulated control and transgenic mice.

relative to protein content, a lower degree of activated c-SRC was evidenced in transgenic animals compared to that in normal mice (Fig. 4A).

Results presented indicate that transgenic mice show a generalized attenuation of EGF signaling in the liver, as the relative response to acute EGF stimulation was lower than that achieved by normal mice or no response was observed depending on the transduction mediator studied. Therefore, we analyzed EGF-induced phosphorylation of the EGFR at an activating residue. For this purpose, phosphorylation at tyrosine 845 was assessed at different time points after EGF injection (Fig. 4B).

In agreement with previous results (González et al. 2010), basal EGFR phosphorylation levels at Tyr 845 were found to be increased in the transgenic mice. Further phosphorylation of the receptor at this residue was induced in normal and transgenic mice upon stimulation (Fig. 4B). However, when phosphorylation levels were expressed in terms of protein content, results showed that the relative amount of EGFR phosphorylated upon EGF administration in the transgenic mice was significantly lower than that in the normal ones (Fig. 4B). The decreased activation of the EGFR upon exogenous stimulation with EGF observed in the GH-overexpressing mice is in accordance with the results previously described for the EGF signaling pathways.

Considering that chronically elevated levels of $\mathrm{GH}$ result in increased hepatic levels of EGFR but a decreased
A

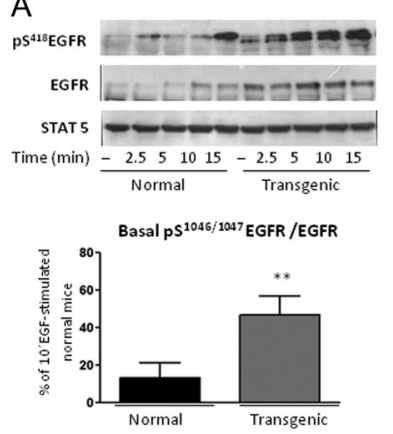

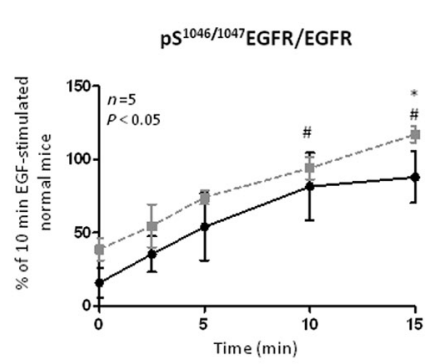

B

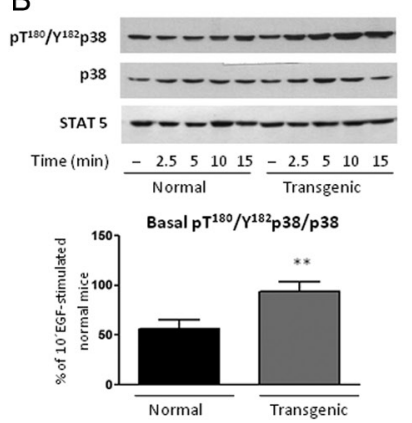

$\mathrm{pT}^{180} / \mathrm{Y}^{182} \mathrm{p} 38 / \mathrm{p} 38$

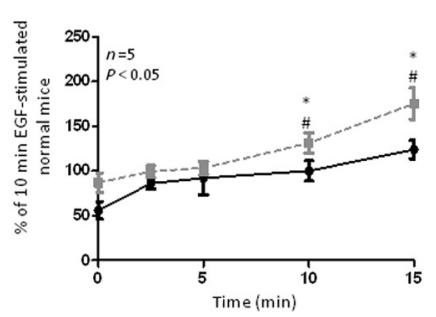

Figure 5

Kinetics of S1046/1047-EGFR and p38 EGF-induced phosphorylation in normal and GH-overexpressing mice liver. Normal and PEPCK-bGH transgenic mice were injected i.p. with saline or EGF ( $2 \mathrm{mg} / \mathrm{kg} \mathrm{BW}$ ), killed after 2.5, 5, 10 or $15 \mathrm{~min}$ and the livers were removed. Equal amounts of solubilized liver protein were separated by SDS-PAGE and subjected to immunoblotting analysis. Reprobing with anti-STAT5 antibody demonstrated similar protein loading in all lanes. Representative immunoblots are shown. Quantification was performed by scanning densitometry and expressed as percent of values measured for EGF (10 min)-stimulated normal mice. Data resulting from quantification analysis were used to calculate the pS1046/1047 EGFR/EGFR (A) and

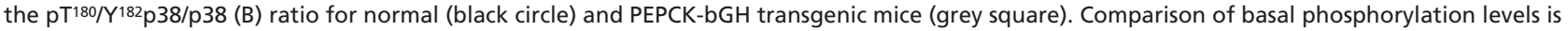
included in each panel. Data are expressed as the mean \pm S.E.M. of the indicated number of subsets $(n)$ of different individuals. Statistical analysis was performed by ANOVA or $t$ student when two pair of subsets were analysed, * and \# denote significant difference at $P<0.05$ compared to non-stimulated control and transgenic mice, respectively, when analysis was performed by ANOVA and ** denote significant difference at $P<0.05$ when basal phosphorylation levels were compared between normal and transgenic mice by Student $t$ test.

http://joe.endocrinology-journals.org DOI: $10.1530 / \mathrm{JOE}-16-0606$
๑) 2017 Society for Endocrinology Printed in Great Britain
Published by Bioscientifica Ltd 
response to EGF in transgenic mice, the phosphorylation status of the EGFR at Ser 1046/1047, an inactivating residue (Theroux et al. 1992), was studied. Basal phosphorylation levels were found to be increased in the liver of transgenic mice compared to those in control animals (Fig. 5A). EGFR phosphorylation at Ser 1046/1047 was induced by EGF in the liver of normal and transgenic mice, reaching high phosphorylation levels $15 \mathrm{~min}$ after treatment. In contrast to results obtained for EGFR phosphorylation at residue Y845, EGFR Ser 1046/1047 phosphorylation levels were higher in the transgenic mice compared to those in normal animals even when phosphorylation was expressed with respect to the protein content (Fig. 5A).

EGFR phosphorylation at the Ser 1046/1047 has been described to be mainly mediated by the p38 MAP kinase (Adachi et al. 2009); therefore, p38 phosphorylation and protein content were assessed in the liver of normal and transgenic mice. As shown in Fig. 5B, basal phosphorylation levels were found to be increased in the liver of transgenic mice compared to those in control animals (Fig. 5B). p38 phosphorylation was induced by EGF in normal and transgenic mice liver. No differences in protein content were observed between normal and transgenic mice. When p38 phosphorylation levels were related to protein content, it was observed that phospho-p38 was significantly induced in normal and transgenic mice liver $10 \mathrm{~min}$ after treatment and remained high at $15 \mathrm{~min}$. However, the phosphorylation levels attained upon EGF stimulation in transgenic mice resulted higher than phosphorylation levels reached in normal mice (Fig. 5B).

\section{Discussion}

To ascertain possible mechanisms underlying the previously described effects of high GH levels over EGFR signaling in the liver of GH-overexpressing mice (González et al. 2010), and the potential implications on EGF-promotion of the cell cycle, kinetic studies of EGFR signaling mediators and analysis of EGF induction of cell cycle modulators were performed in the liver of GH-overexpressing transgenic mice.

EGF-induced STAT3, STAT5 and ERK1/2 phosphorylation was analyzed at different time points after growth factor stimulation. Contrary to results previously obtained for AKT, which showed transient phosphorylation of the kinase at short times (Díaz et al. 2012), STAT3 and STAT5 phosphorylation was not stimulated by EGF in transgenic mice liver at any time studied, and ERK1/2 phosphorylation relative to protein content was reduced with respect to normal levels during the interval considered. As it was previously proposed (González et al. 2010), decreased EGF induction of STATs phosphorylation may be attributed to reduced recruitment of the transcription factors by the receptor. In the case of STAT5, decreased association with the receptor was correlated with its increased binding to the tyrosine phosphatase SHP-2 (González et al. 2010). Diminished ERK1/2 response to EGF stimulation might rely on alternative attenuation mechanisms.

Considering the desensitization of STATs signaling and the decreased response of ERK1/2 and AKT upon EGF stimulation described in the liver of the GH-overexpressing transgenic mice, it was of interest to ascertain the consequences of high GH levels over EGF induction of regulatory proteins involved in the promotion of cell proliferation. c-MYC was one of the cell cycle inductors studied as it is a potent oncogene commonly involved in the pathogenesis of human cancers (Lin et al. 2010, Gabay et al. 2014). c-MYC is a pleiotropic signaling mediator that promotes growth and expansion of somatic cells, its activation results in the upregulation of D-type CYCLINs and concomitant downregulation of multiple negative cell cycle inhibitors like p15, p21 and p27 (Gartel $\&$ Shchors 2003). We have previously reported that c-MYC protein and mRNA content are increased in the liver of transgenic mice overexpressing GH (Miquet et al. 2013), which was not evidenced in the present study because analysis was performed in parallel with samples from stimulated mice; however, a tendency to higher $c-M y c$ expression levels in the transgenic mice was noticed. EGF induction of c-MYC was lower in the transgenic mice compared to that in normal animals, in agreement with EGF signaling desensitization.

c-FOS and c-JUN are transcription factors rapidly and transiently induced upon stimulation and hence referred to as immediate early genes. c-Fos is a proto-oncogene and part of the FOS family of transcription factors (MildeLangosch 2005); it is upregulated in response to several mitogenic signals, including EGF (Curran et al. 1985). c-FOS can bind to c-JUN, a member of the JUN family of transcription factors, resulting in the activator protein-1 complex (AP-1) (Chiu et al. 1988). AP-1, in turn, induces the expression of target genes that regulate proliferation and survival (Vesely et al. 2009). c-Fos and c-Jun-upregulated expression has been associated with cancer development, including hepatocarcinoma (Milde-Langosch 2005, Liu et al. 2012). Basal c-FOS and c-JUN protein content and mRNA expression were also described to be increased in the liver of transgenic mice overexpressing $\mathrm{GH}$

Published by Bioscientifica Ltd. 
(Miquet et al. 2013). Such increased basal levels were not evidenced when samples were analyzed in parallel with those of EGF-stimulated mice. Regarding EGF induction, c-FOS levels were lower in the liver of transgenic mice, but c-JUN levels were similar in both animal models.

Studies of early gene induction upon EGF stimulation were in agreement with the observed decreased activation by EGF of its pro-mitogenic signaling pathways in the liver of the transgenic mice. However, the level of expression of the transcription factors after EGF administration was different, whereas c-MYC was not significantly induced by EGF in the transgenic mice, c-FOS augmented upon stimulation but to lower levels than that in normal mice. On the other hand, c-JUN was induced to similar levels in control and transgenic mice. STAT3 and STAT5 have been reported to promote $c-M y c$ expression upon stimulation with growth factors other than EGF (Caló et al. 2003, Wu et al. 2014). Results from these studies might imply that EGF signaling through the STATs could also have an important role in $c-M y c$ expression in mice liver because absence of STATs response upon EGF administration was associated with desensitization of c-MYC induction. However, decreased expression of c-Fos upon EGF stimulation might be attributed to reduced activation of ERK1/2 and AKT (Karin 1995, Liang \& Slingerland 2003). On the other hand, c-Jun transcriptional regulation mainly accounts on JNK activation (Dérijard et al. 1994, Karin 1995), which might not be downregulated in the liver of the GH-overexpressing mice. It should be considered that EGFR phosphorylation at different residues triggers different signaling pathways (Zhang et al. 2005); the mechanisms involved in GH desensitization or attenuation of EGF signaling would impact preferentially certain signaling cascades.

Four CYCLIN families are responsible for the activation of the cyclin-dependent kinases (CDKs) in different stages of the cell cycle. Particularly, CDK4/6CYCLIN D and CDK2-CYCLIN E complexes are sequentially required to promote cell cycle entrance from quiescence, progression through the G1 phase and transition from G1 into $S$ phase in response to mitogenic stimulation (Santamaria \& Ortega 2006). Considering that CYCLINs D1 and E are directly involved in cell cycle promotion, their levels were analyzed by immunoblotting and RT-qPCR. CYCLIN D1 induction showed similar levels of expression to c-JUN, which is a potent activator of the CYCLIN; however, the expression levels of CyclinD1 were not reflected in CYCLIN E content, whose expression depends not only on CDK4/6-CYCLIN D activation but also on c-MYC induction. Overall, results suggest a reduced induction of the cell cycle by acute EGF stimulation in transgenic mice despite increased levels of EGFR protein content. Therefore, there is no direct correlation between EGFR levels (González et al. 2010) and the EGF induction of early genes and CYCLINs. GH-overexpressing transgenic mice showed increased EGFR hepatic levels (González et al. 2010) but reduced or similar EGF induction of c-MYC, c-JUN, c-FOS and CYCLINs with respect to normal siblings. These results are different from those described for normal mice receiving intermittent injections of GH during a short period (Díaz et al. 2014). In that case, the treatment induced a significant upregulation of the receptor and, concomitantly, an increased expression of early genes involved in cell cycle control. The difference between both models is the nature of GH influence over EGF signaling pathways; chronic and continuous circulating GH levels caused an upregulation of EGFR liver content but a desensitization of EGF signaling (González et al. 2010, Díaz et al. 2012), whereas short-term treatment with intermittent injections of EGF also produced an increase in EGFR protein content but upregulated EGF signaling (Díaz et al. 2014). Therefore, the next goal was to elucidate possible mechanisms involved in the attenuation of EGF signal in the liver of transgenic mice. For this purpose, activation of molecules upstream the STATs, ERK1/2 and AKT, namely c-SRC and EGFR, was studied.

c-SRC activation is promoted by several growth factors, including EGF; it plays a critical role in the regulation of cell proliferation, migration, adhesion, angiogenesis and immune function. Induction of c-SRC kinase activity results in the phosphorylation of different substrates, including Tyr 845 residue of EGFR (Biscardi et al. 1999, Kloth et al. 2003). c-SRC protein content and basal phosphorylation are increased in the transgenic mice overexpressing GH (Miquet et al. 2008); however, its activation upon EGF administration has not been previously studied. EGF stimulation during different intervals revealed that the kinase phosphorylation is significantly induced in normal mice while not in the transgenic animals.

EGFR basal phosphorylation and protein content are also augmented in the liver of the GH-overexpressing transgenic mice (Miquet et al. 2008). When EGFR phosphorylation at the activating residue Tyr845 was studied after different stimulation times with EGF, reduced EGFR activation was evidenced in the liver of transgenic mice compared to that in the normal animals. Results suggest that chronically elevated levels of GH present in transgenic mice affect EGFR function despite inducing an increase in EGFR levels.

Published by Bioscientifica Ltd. 
Phosphorylation of EGFR on serine residues represents a mechanism for attenuation of EGFR activity. Among the major sites of serine phosphorylation of the EGFR, serine 1046/1047 (Ser 1046/1047) is required for EGFR desensitization (Countaway et al. 1992, Theroux et al. 1992). Mutational removal of these negative regulatory phosphorylation sites causes the potentiation of signal transduction by the EGFR (Theroux et al. 1992). Recently, EGFR desensitization mechanisms have been discriminated between those induced by EGF binding to its receptor (homologous desensitization) and those triggered by treatments other than ligand binding (heterologous desensitization) (Yamamoto et al. 2014). Heterologous desensitization of the EGFR would be induced by serine phosphorylation of the EGFR via the p38 mitogen-activated protein kinase (p38 MAP kinase) pathway in various cell lines (Adachi et al. 2009, 2010). It was therefore of interest to study EGF-induced phosphorylation of EGFR at serine 1046/1047 and p38 activation in normal and transgenic mice. Basal as well as EGF-induced Ser 1046/1047-EGFR levels achieved in the transgenic mice were higher than those described for normal mice, which correlated with augmented activation of p38 in the liver of the transgenic animals. Therefore, concomitant to decreased EGF-induced signaling in the liver of the transgenic mice, p38 activation and EGFR phosphorylation at the Ser 1046/1047 were increased in transgenic mice. Hyperactivation of p38 and increased phosphorylation of the EGFR at the Ser residues might represent a desensitization mechanism triggered by continuously high GH levels to attenuate response to EGF.

Results from this research work demonstrate that ERK1/2-, STATs- and c-SRC-mediated EGFR signaling is attenuated upon exogenous EGF stimulation for different intervals in the liver of transgenic mice overexpressing GH. Such effects are in accordance with a low activation of the EGFR upon EGF stimulation despite its elevated amount in the liver of the transgenic mice, as well as with a decreased induction of the transcription factors c-MYC and c-FOS and the cell cycle promoter CYCLIN E. Decreased induction of EGF signaling was associated with increased phosphorylation of the EGFR in serine 1046/1047, which had been reported to attenuate EGFR signaling; and increase activation of $\mathrm{p} 38$, a MAPK that has been involved in phosphorylation of EGFR at negative regulatory residues.

Transgenic mice overexpressing GH display high levels of hepatocellular replication throughout lifespan, and old animals frequently develop liver tumors (Snibson 2002). Several hepatocellular alterations as well as dysregulation of oncogenic pathways have been described in the liver of these transgenic mice (Miquet et al. 2013). Particularly, immunohistochemistry and immunoblotting analysis of the S-phase-related proliferating cell nuclear antigen (PCNA) evidenced a marked increase in transgenic mice, which was associated with upregulation of molecules involved in cell proliferation like CYCLIN D1, CYCLIN E, c-MYC, c-JUN and c-FOS (Miquet et al. 2013). Upregulation of these cell cycle modulators might reflect the increased protein levels and basal phosphorylation of EGFR, c-SRC and ERK1/2 in the liver of the transgenic mice (Miquet et al. 2008, 2013). However, further induction of EGF signaling upon exogenous EGF administration is impaired in this animal model.

The function of epidermal growth factor receptor has been described to be negatively regulated in the M phase (Gomez-Cambronero 1999, Dangi \& Shapiro 2005). Ligand-induced autophosphorylation and downstream signaling of the EGFR were demonstrated to be tightly suppressed in the $\mathrm{M}$ phase due to a decrease in ligand-binding affinity (Kiyokawa et al. 1997). Hyperphosphorylation at serine and/or threonine residues was associated with unresponsiveness of cells to EGF (Kiyokawa et al. 1997). In accordance, attenuation of EGF signaling and decreased EGF induction of cell cycle mediators was observed in transgenic mice overexpressing growth hormone. Although elevated GH levels present in transgenic mice upregulate basal activation and expression of mitogenic mediators in liver, at the same time, trigger compensatory mechanisms to downregulate response to pro-proliferative signals. In accordance, desensitization of GH signaling was previously described in the transgenic mice overexpressing $\mathrm{GH}$, which implied upregulation of the SOCS protein CIS (González et al. 2002, Miquet et al. 2004). Desensitization would not be restricted to the signaling pathways triggered by the homologous receptor, it would also affect receptors that do not bind GH like the EGFR (González et al. 2010). In this case, the inhibitory mechanism would involve hyperphosphorylation of the EGFR at Ser residues, despite of which, additional inhibitory mechanisms cannot be excluded.

\section{Declaration of interest}

The authors declare that there is no conflict of interest that could be perceived as prejudicing the impartiality of the research reported.
Published by Bioscientifica Ltd 


\section{Funding}

L G, J G M, A I S, M B F and D T are Career Investigators of CONICET. $M E D$ and S P R are supported by a fellowship from CONICET and P E I is supported by a fellowship from UBA. Support for these studies was provided by UBA (20020130200005BA), CONICET (PIP-320), and ANPCYT (PICT 2013-937 and 2013-2953) to D T and L G, and by National Institute on Aging (grant numbers AG19899 and AG031736) to A B.

\section{References}

Adachi S, Natsume H, Yamauchi J, Matsushima-Nishiwaki R, Joe AK, Moriwaki H \& Kozawa O 2009 p38 MAP kinase controls EGF receptor downregulation via phosphorylation at Ser1046/1047. Cancer Letters 277 108-113. (doi:10.1016/j.canlet.2008.11.034)

Adachi S, Yasuda I, Nakashima M, Yamauchi T, Yamauchi J, Natsume H, Moriwaki H \& Kozawa O 2010 HSP90 inhibitors induce desensitization of EGF receptor via p38 MAPK-mediated phosphorylation at Ser1046/1047 in human pancreatic cancer cells. Oncology Reports 23 1709-1714. (doi:10.3892/or_00000815)

Arteaga CL \& Engelman JA 2014 ERBB receptors: from oncogene discovery to basic science to mechanism-based cancer therapeutics. Cancer Cell 25 282-303. (doi:10.1016/j.ccr.2014.02.025)

Bartke A 2003 Can growth hormone (GH) accelerate aging? Evidence from GH-transgenic mice. Neuroendocrinology 78 210-216. (doi:10.1159/000073704)

Belsches AP, Haskell MD \& Parsons SJ 1997 Role of c-Src tyrosine kinase in EGF-induced mitogenesis. Frontiers in Bioscience 2 d501-d518. (doi:10.2741/A208)

Berasain C \& Avila MA 2014 The EGFR signaling system in the liver: from hepatoprotection to hepatocarcinogenesis. Journal of Gastroenterology 49 9-23. (doi:10.1007/s00535-013-0907-x)

Biscardi JS, Maa MC, Tice DA, Cox ME, Leu TH \& Parsons SJ 1999 c-Srcmediated phosphorylation of the epidermal growth factor receptor on Tyr845 and Tyr1101 is associated with modulation of receptor function. Journal of Biological Chemistry 274 8335-8343. (doi:10.1074/ jbc.274.12.8335)

Bromberg J \& Darnell JE Jr 2000 The role of STATs in transcriptional control and their impact on cellular function. Oncogene $\mathbf{1 9}$ 2468-2473. (doi:10.1038/sj.onc.1203476)

Buckley AF, Burgart LJ, Sahai V \& Kakar S 2008 Epidermal growth factor receptor expression and gene copy number in conventional hepatocellular carcinoma. American Journal of Clinical Pathology 129 245-251. (doi:10.1309/WF10QAAED3PP93BH)

Calò V, Migliavacca M, Bazan V, Macaluso M, Buscemi M, Gebbia N \& Russo A 2003 STAT proteins: from normal control of cellular events to tumorigenesis. Journal of Cellular Physiology 197 157-168. (doi:10.1002/jcp.10364)

Chiu R, Boyle WJ, Meek J, Smeal T, Hunter T \& Karin M 1988 The c-Fos protein interacts with c-Jun/AP-1 to stimulate transcription of AP-1 responsive genes. Cell 54 541-552. (doi:10.1016/00928674(88)90076-1)

Countaway JL, Nairn AC \& Davis RJ 1992 Mechanism of desensitization of the epidermal growth factor receptor protein-tyrosine kinase. Journal of Biological Chemistry 267 1129-1140.

Curran T, Bravo R \& Müller R 1985 Transient induction of c-fos and c-myc in an immediate consequence of growth factor stimulation. Cancer Surveys 4 655-681.

Dangi S \& Shapiro P 2005 Cdc2-mediated inhibition of epidermal growth factor activation of the extracellular signal-regulated kinase pathway during mitosis. Journal of Biological Chemistry $28024524-24531$. (doi:10.1074/jbc.M414079200)

Dérijard B, Hibi M, Wu IH, Barrett T, Su B, Deng T, Karin M \& Davis RJ 1994 JNK1: a protein kinase stimulated by UV light and Ha-Ras that binds and phosphorylates the c-Jun activation domain. Cell 76 1025-1037. (doi:10.1016/0092-8674(94)90380-8)

Díaz ME, González L, Miquet JG, Martinez CS, Sotelo AI, Bartke A \& Turyn D 2012 Growth hormone modulation of EGF-induced PI3K-Akt pathway in mice liver. Cellular Signaling 24 514-523. (doi:10.1016/j. cellsig.2011.10.001)

Díaz ME, Miquet JG, Rossi S, Irene PE, Sotelo AI, Frungieri MB, Turyn D \& González L 2014 GH administration patterns differently regulate epidermal growth factor signaling. Journal of Endocrinology 221 317-331. (doi:10.1530/JOE-13-0447)

Frungieri MB, Weidinger S, Meineke V, Kohn FM \& Mayerhofer A 2002 Proliferative action of mast-cell tryptase is mediated by PAR2, COX2, prostaglandins, and PPARg: possible relevance to human fibrotic disorders. PNAS 99 15072-15077. (doi:10.1073/ pnas.232422999)

Gabay M, Li Y \& Felsher DW 2014 MYC activation is a hallmark of cancer initiation and maintenance. Cold Spring Harbor Perspectives in Medicine 4 655-681. (pii: a014241, doi:10.1101/cshperspect.a014241)

Gartel AL \& Shchors K 2003 Mechanisms of c-myc-mediated transcriptional repression of growth arrest genes. Experimental Cell Research 283 17-21. (doi:10.1016/S0014-4827(02)00020-4)

Gomez-Cambronero J 1999 p42-MAP kinase is activated in EGFstimulated interphase but not in metaphase-arrested HeLa cells. FEBS Letters 443 126-130. (doi:10.1016/S0014-5793(98)01685-8)

González L, Miquet JG, Sotelo AI, Bartke A \& Turyn D 2002 Cytokineinducible $\mathrm{SH} 2$ protein up-regulation is associated with desensitization of GH signaling in GHRH-transgenic mice. Endocrinology 143 386-394. (doi:10.1210/endo.143.2.8616)

González L, Díaz ME, Miquet JG, Sotelo AI, Fernández D, Dominici FP, Bartke A \& Turyn D 2010 GH modulates hepatic epidermal growth factor signaling in the mouse. Journal of Endocrinology 204 299-309. (doi:10.1677/JOE-09-0372)

Henson ES \& Gibson SB 2006 Surviving cell death through epidermal growth factor (EGF) signal transduction pathways: implications for cancer therapy. Cellular Signaling 18 2089-2097. (doi:10.1016/j. cellsig.2006.05.015)

Huang Y, Kim SO, Jiang J \& Frank SJ 2003 Growth hormone-induced phosphorylation of epidermal growth factor (EGF) receptor in 3T3-F442A cells. Modulation of EGF-induced trafficking and signaling. Journal of Biological Chemistry 278 18902-18913. (doi:10.1074/jbc.M300939200)

Huang Y, Chang Y, Wang X, Jiang J \& Frank SJ 2004 Growth hormone alters epidermal growth factor receptor binding affinity via activation of extracellular signal-regulated kinases in 3T3-F442A cells. Endocrinology 145 3297-3306. (doi:10.1210/en.2003-1658)

Huang Y, Li X, Jiang J \& Frank SJ 2006 Prolactin modulates phosphorylation, signaling and trafficking of epidermal growth factor receptor in human T47D breast cancer cells. Oncogene 25 7565-7576. (doi:10.1038/sj.onc.1209740)

Hynes NE \& MacDonald G 2009 ErbB receptors and signaling pathways in cancer. Current Opinion in Cell Biology 21 177-184. (doi:10.1016/j. ceb.2008.12.010)

Ito Y, Takeda T, Sakon M, Tsujimoto M, Higashiyama S, Noda K, Miyoshi E, Monden M \& Matsuura N 2001 Expression and clinical significance of erb-B receptor family in hepatocellular carcinoma. British Journal of Cancer 18 1377-1383. (doi:10.1054/bjoc.2000.1580)

Jansson JO, Ekberg S, Hoath SB, Beamer WG \& Frohman LA 1988 Growth hormone enhances hepatic epidermal growth factor receptor concentration in mice. Journal of Clinical Investigation 82 1871-1876. (doi:10.1172/JCI113804)

Jenkins PJ 2006 Cancers associated with acromegaly. Neuroendocrinology 83 218-223. (doi:10.1159/000095531)

Karin M 1995 The regulation of AP-1 activity by mitogen-activated protein kinases. Journal of Biological Chemistry 270 16483-16486. (doi:10.1074/jbc.270.28.16483) http://joe.endocrinology-journals.org

DOI: $10.1530 / J O E-16-0606$
() 2017 Society for Endocrinology Printed in Great Britain 
Kiyokawa N, Lee EK, Karunagaran D, Lin SY \& Hung MC 1997 Mitosisspecific negative regulation of epidermal growth factor receptor, triggered by a decrease in ligand bindingand dimerization, can be overcome by overexpression of receptor. Journal of Biological Chemistry 272 18656-18665. (doi:10.1074/jbc.272.30.18656)

Kloth MT, Laughlin KK, Biscardi JS, Boerner JL, Parsons SJ \& Silva CM 2003 STAT5b, a mediator of synergism between c-Src and the epidermal growth factor receptor. Journal of Biological Chemistry $\mathbf{2 7 8}$ 1671-1679. (doi:10.1074/jbc.M207289200)

Li X, Huang Y, Jiang J \& Frank SJ 2008 ERK-dependent threonine phosphorylation of EGF receptor modulates receptor downregulation and signaling. Cellular Signaling 20 2145-2155. (doi:10.1016/j. cellsig.2008.08.006)

Liang J \& Slingerland JM 2003 Multiple roles of the PI3K/PKB (Akt) pathway in cell cycle progression. Cell Cycle 2 339-345.

Lin CP, Liu CR, Lee CN, Chan TS \& Liu HE 2010 Targeting c-Myc as a novel approach for hepatocellular carcinoma. World Journal of Hepatology 2 16-20. (doi:10.4254/wjh.v2.i1.16)

Liu Z, Yan R, Al-Salman A, Shen Y, Bu Y, Ma J, Luo DX, Huang C, Jiang Y, Wilber A, et al. 2012 Epidermal growth factor induces tumour marker AKR1B10 expression through activator protein-1 signalling in hepatocellular carcinoma cells. Biochemical Journal 442 273-282. (doi:10.1042/BJ20111322)

Loeper S \& Ezzat S 2008 Acromegaly: re-thinking the cancer risk. Reviews in Endocrine and Metabolic Disorders 9 41-58. (doi:10.1007/s11154-0079063-z)

McGrane MM, Yun JS, Moorman AF, Lamers WH, Hendrick GK, Arafah BM, Park EA, Wagner TE \& Hanson RW 1990 Metabolic effects of developmental, tissue-, and cell-specific expression of a chimeric phosphoenolpyruvate carboxykinase (GTP)/bovine growth hormone gene in transgenic mice. Journal of Biological Chemistry 265 22371-22379.

Milde-Langosch K 2005 The Fos family of transcription factors and their role in tumourigenesis. European Journal of Cancer 41 2449-2461. (doi:10.1016/j.ejca.2005.08.008)

Miquet JG, Sotelo AI, Bartke A \& Turyn D 2004 Suppression of growth hormone $(\mathrm{GH})$ Janus tyrosine kinase 2/signal transducer and activator of transcription 5 signaling pathway in transgenic mice overexpressing bovine GH. Endocrinology 145 2824-2832. (doi:10.1210/en.2003-1498)

Miquet JG, Gonzalez L, Matos MN, Hansen C, Louis A, Bartke A, Turyn D \& Sotelo AI 2008 Transgenic mice overexpressing GH exhibit hepatic upregulation of $\mathrm{GH}$-signaling mediators involved in cell proliferation. Journal of Endocrinology 198 317-330. (doi:10.1677/JOE-08-0002)

Miquet JG, Freund T, Martinez CS, González L, Diaz ME, Micucci GP, Zotta E, Boparai RK, Bartke A, Turyn D, et al. 2013 Hepatocellular alterations and dysregulation of oncogenic pathways in the liver of transgenic mice overexpressing growth hormone. Cell Cycle $\mathbf{1 2}$ 1042-1057. (doi:10.4161/cc.24026)
Nasi S, Ciarapica R, Jucker R, Rosati J \& Soucek L 2001 Making decisions through Myc. FEBS Letters 490 153-162. (doi:10.1016/S00145793(01)02118-4)

Santamaria D \& Ortega S 2006 Cyclins and CDKS in development and cancer: lessons from genetically modified mice. Frontiers in Bioscience 11 1164-1188. (doi:10.2741/1871)

Shaulian E \& Karin M 2001 AP-1 in cell proliferation and survival. Oncogene 20 2390-2400. (doi:10.1038/sj.onc.1204383)

Snibson KJ 2002 Hepatocellular kinetics and the expression of growth hormone $(\mathrm{GH})$ in the livers and liver tumours of GH-transgenic mice. Tissue and Cell 34 88-97. (doi:10.1016/S0040-8166(02)00012-5)

Theroux SJ, Stanley K, Campbell DA \& Davis RJ 1992 Mutational removal of the major site of serine phosphorylation of the epidermal growth factor receptor causes potentiation of signal transduction: role of receptor down-regulation. Molecular Endocrinology 6 1849-1857. (doi:10.1210/mend.6.11.1480174)

Vesely PW, Staber PB, Hoefler G \& Kenner L 2009 Translational regulation mechanisms of AP-1 proteins. Mutation Research 682 7-12. (doi:10.1016/j.mrrev.2009.01.001)

Wu WY, Kim H, Zhang CL, Meng XL \& Wu ZS 2014 Loss of suppressors of cytokine signaling 3 promotes aggressiveness in hepatocellular carcinoma. Journal of Investigative Surgery 27 197-204. (doi:10.3109/08 941939.2013.873098)

Yamamoto H, Higa-Nakamine S, Noguchi N, Maeda N, Kondo Y, Toku S, Kukita I \& Sugahara K 2014 Desensitization by different strategies of epidermal growth factor receptor and ErbB4. Journal of Pharmacological Sciences 124 287-293. (doi:10.1254/jphs.13R11CP)

Yamauchi T, Ueki K, Tobe K, Tamemoto H, Sekine N, Wada M, Honjo M, Takahashi M, Takahashi T, Hirai H, et al. 1998 Growth hormoneinduced tyrosine phosphorylation of EGF receptor as an essential element leading to MAP kinase activation and gene expression. Endocrine Journal 45 (Supplement) S27-S31. (doi:10.1507/endocrj.45. Suppl_S27)

Yarden Y \& Sliwkowski MX 2001 Untangling the ErbB signaling network. Nature Reviews Molecular Cell Biology 2 127-137. (doi:10.1038/35052073)

Yarden Y \& Pines G 2012 The ERBB network: at last, cancer therapy meets systems biology. Nature Reviews Cancer 12 553-563. (doi:10.1038/ nrc3309)

Zhang Y, Wolf-Yadlin A, Ross PL, Pappin DJ, Rush J, Lauffenburger DA \& White FM 2005 Time-resolved mass spectrometry of tyrosine phosphorylation sites in the epidermal growth factor receptor signaling network reveals dynamic modules. Molecular and Cellular Proteomics 4 1240-1250. (doi:10.1074/mcp.M500089-MCP200)

Zerrad-Saadi A, Lambert-Blot M, Mitchell C, Bretes H, Collin de l'Hortet A, Baud V, Chereau F, Sotiropoulos A, Kopchick JJ, Liao L, et al. $2011 \mathrm{GH}$ receptor plays a major role in liver regeneration through the control of EGFR and ERK1/2 activation. Endocrinology 152 2731-2741. (doi:10.1210/en.2010-1193)

Received in final form 29 January 2017

Accepted 21 February 2017

Accepted Preprint published online 21 February 2017 http://joe.endocrinology-journals.org

DOI: $10.1530 / \mathrm{JOE}-16-0606$
๑) 2017 Society for Endocrinology Printed in Great Britain
Published by Bioscientifica Ltd. 